\title{
KOMUNIKASI PEMASARAN PRODUK KOMODITAS LOKAL BERBASIS KOMUNITAS MELALUI PENGGUNAAN MEDIA (Studi Kasus FruitsUp, UMKM di Jatinangor)
}

\author{
Santi Susanti', Dwi Purnomo², Wahyu Gunawan ${ }^{3}$ dan Diana Sari ${ }^{4}$ \\ ${ }^{1}$ Fakultas Ilmu Komunikasi, Universitas Padjadjaran \\ ${ }^{2}$ Fakultas Teknologi Industri Pangan, Universitas Padjadjaran \\ ${ }^{3}$ Fakultas Ilmu Sosial dan Ilmu Politik, Universitas Padjadjaran \\ ${ }^{4}$ Fakultas Ekonomi dan Bisnis Universitas Padjadjaran \\ Jl. Raya Bandung-Sumedang Km. 21 Jatinangor, 456363 \\ E-mail: santi.susanti@unpad.ac.id
}

\begin{abstract}
ABSTRAK, Fruits Up merupakan salah satu produk UMKM Unpad yang berhasil melakukan diversifikasi produk olahan mangga menjadi puree buah. Pengembangan bisnis melalui Fruters Model mampu menjadikan bisnis Fruits Up yang dimulai dari skala kecil berjalan selama tiga tahun dan berkembang cukup baik dari sisi asset maupun kekayaan sumber daya manusianya. Meski demikian, pengembangan masih dilakukan Fruits $U p$, salah satunya perluasan pemasaran, agar produk dapat menjangkau lebih banyak target pasar sehingga skala penjualan dan skala produksi meningkat. Penelitian ini bertujuan mengetahui strategi pemasaran Fruits Up dalam menjangkau target pasar lebih luas melalui media massa dan media jejaring sosial. Hasil penelitian menunjukkan, televisi, radio, surat kabar dan media sosial dijadikan saluran komunikasi untuk mengenalkan FrutsUp secara luas kepada masyarakat. Perancangan dan penyampaian pesan disesuaikan dengan media yang digunakan. Melalui media massa dan jejaring sosial, diharapkan selain dikenal luas, FuitsUp dapat memberikan nilai tambah baik dari sisi pemasaran produk, maupun dari sisi peningkatan kesejahteraan dan kesehatan masyarakat.
\end{abstract}

Kata kunci: FruitsUp; Fruters Model; komunikasi pemasaran; media; nilai tambah

\section{MARKETING COMMUNICATION OF LOCAL COMMODITIES PRODUCTS WITH COMMUNITY- BASED THROUGH MEDIA USAGE (Case Study of FruitsUp, UMKM in Jatinangor)}

\begin{abstract}
FruitsUp is one of the UMKM Unpad products that successfully diversify the processed mango products into fruit puree. Fruters Model Business development is enable to make the business run for three years and develop quite well in terms of assets and wealth of human resources. Nevertheless, FruitsUp's development is still underway, one of which is the expansion of marketing, so the product can reach more target market, the scale of sales and production increases also. This study aims to determine the marketing strategy of Fruits Up to reach the target market more broadly through the mass media and social media. The results show that mass media and social media became a channel of communication to introduce FruitsUp broadly. The use of mass media and social networking is expected that besides being widely known, FruitsUp can provide added value in terms of product marketing, as well as the improvement of community welfare and health.
\end{abstract}

Key words: FruitsUp; Fruters Model; marketing communication; media, added value

PENDAHULUAN

Jawa Barat termasuk ke dalam salah satu produsen mangga terbesar di Indonesia bersama dengan Jawa Timur, Jawa Tengah, Sulawesi Selatan, NTB dan NTT (Deliana, dkk., 2014). Salah satu varian yang banyak dihasilkan adalah mangga gedong gincu. Wilayah Cirebon, Indramayu, Majalengka dan Kuningan (Ciayumajakuning) adalah penghasil mangga gedong gincu di Jawa Barat. Pada setiap panen, jumlah mangga seringkali berlebih. Akibatnya, harga jualnya menjadi turun dan banyak mangga yang dibuang.

Pada tahun 2014, sejumlah mahasiswa Fakultas Teknik Industri Pertanian (FTIP) Universitas Padjadjaran, yang sedang merintis wirausaha, menawarkan solusi kepada para petani mangga di Ciayumajakuning, berupa input teknologi pengelolaan pangan yang mengubah buah mangga utuh menjadi bubur buah atau puree, yang dapat dikonsumsi kapanpun, tanpa terikat musim mangga. Dengan demikian, tidak ada lagi mangga yang terbuang pascapanen dan nilai tambah pada mangga hasil panen para petani pun meningkat. Adanya kepastian hilirisasi produk menjadikan para petani bersemangat merawat tanaman mangganya. Jenis mangga yang diolah saat ini adalah gedong gincu, harum manis dan kuweni. Mangga yang sudah diolah menjadi bubur buah tersebut kemudian dikemas kembali ke dalam botol menjadi produk minuman mangga berlabel FruitsUp.

Pengembangan produk yang dilakukan Fruits Up menggunakan konsep sociopreneurship, yakni kegiatan sosial melalui jiwa kewirausahaan. Masyarakat dibantu untuk mandiri melalui kewirausahaan. Pendekatan sociopreneurship dirancang untuk memiliki rantai manfaat yang panjang, sehingga memberikan nilai pada objek sosial yang ditujunya, serta diarahkan untuk menyebar nilai guna dan nilai tambah yang besar bagi masyarakat. (unpad.ac.id, 21/11/2014).

Konsep sociopreneurship yang ditawarkan FruitsUp, memiliki profit dan benefit bagi para stakeholder yang terlibat di dalamnya. Profit yang diperoleh digunakan 
sebagai sumber pembiayaan pergerakan petani dan komunitas lokal yang bermanfaat bagi pengembangan usaha. Benefitnya, dengan mengubah mangga menjadi bubur buah atau puree berkualitas premium, FruitsUp memberi dampak positif pada kesejahteraan petani mangga di kawasan Ciayumajakuning.

Tiga tahun sejak dirintis tahun 2014 oleh Mahadiansyah Alhadi, Bambang Bayu Febianto dan Gian Rizky Pratama, FruitsUp berkembang dan menjadi badan usaha bernama CV. Ormund Indonesia. Konsep sociopreneurship menjadikan Fruits Up sebagai poros kolaborasi dari setiap mitranya. Model bisnis FruitsUp diarahkan untuk menjadi usaha yang memiliki nilai (value) yang tinggi, dan tidak terjebak pada visi untuk membesarkan bisnis dalam tempo yang singkat. Dalam dua tahun, perkembangan bisnisnya cukup baik dengan asset yang dimiliki kurang lebih Rp. 400.000.000, dengan kekayaan sumber daya manusia sebagai modal utamanya.

Walau sudah mulai berkembang, Fruits $U p$ masih memiliki keterbatasan, salah satunya dalam pemasaran. Saat ini, pemasaran masih fokus pada wilayah Bandung dan Jakarta, dengan mengandalkan reseller yang sebagian besar adalah ibu-ibu rumah tangga daerah perkotaan serta membuka gerai-gerai penjualan di cafe dan restoran yang bekerja sama dengan Fruits Up. Mengikuti perkembangan teknologi saat ini, FruitsUp pun memanfaatkan media berbasiskan internet sebagai media pemasaran. Cara tersebut mampu membuahkan hasil dan membuat FruitsUp dikenal. Tertarik akan keberhasilan Fruits $U p$ dalam mengembangkan bisnisnya, maka penelitian ini bertujuan untuk mengetahui strategi komunikasi pemasaran yang dilakukan FruitsUp dalam memperluas pemasaran.

Komunikasi pemasaran digunakan untuk menginformasikan, memengaruhi dan dapat meningkatkan konsumen baik secara langsung maupun tidak langsung. Marcomm Wise (Tsikirayi, Muchenje, \& Katsidzira, 2013) mendefinisikan komunikasi pemasaran meliputi semua strategi, taktik, dan kegiatan dalam mendapatkan pesan pemasaran yang diinginkan untuk target pasar yang dituju, terlepas dari menggunakan media. Komunikasi pemasaran atau marketing communication merupakan sebuah metode yang dapat memajukan dan mengembagkan suatu lembaga pendidikan maupun sebuah organisasi, sehingga manajemen pemasaran yang baik harus diutamakan. (Riyanto \& Triono, 2017).

Penelitian terkait komunikasi pemasaran telah pula dilakukan oleh beberapa peneliti, di antaranya adalah penelitian Meliza Hendri mengenai Pengaruh Komunikasi Pemasaran terhadap Keputusan Pembelian Teh Kotak Ultra Rasa Melati oleh Remaja di Kota Bandung. Penekanan komunikasi pemasaran melalui kegiaan promosi dan nonpromosi. Hasil penelitian menunjukkan bahwa komunikasi pemasaran berpengaruh terhadap keputusan pembelian Teh Kotak Rasa Melati oleh remaja di Kota Bandung. Akan tetapi, kegiatan nonpromosi memberikan kontribusi pengaruh lebih besar daripada kegiatan promosi.
Penelitian berikutnya adalah Komunikasi Pemasaran Usaha Kuliner dalam Menghadapi Persaingan (Studi Deskriptif Kualitatif Kegiatan Komunikasi Pemasaran Cafe "Gerobak Cokelat" dalam Menghadapi Persaingan di Kota Solo) yang dilakukan oleh Akbar Prayogo dan Adolfo Eko Setyanto dari Universitas Sebelas Maret Surakarta. Hasil penelitiannya menunjukkan, Gerobak Cokelat Café melakukan kegiatan pemasaran seperti promosi penjualan, periklanan, publisitas, humas dan word of mouth. Dari kegiatan ini kegiatan komunikasi pemasaran yang paling efektif adalah word of mouth dan twitter sedangkan aktivitas komunikasi pemasaran yang tidak bisa menembus konsumen adalah media elektronik iklan. Strategi komunikasi pemasaran yang dibutuhkan untuk memenangkan persaingan pasar adalah dengan membunuh produk lawan, mengubah tagline, penggunaan saluran media baru dan strategi aplikasi komunikasi media tertentu. Dari dua penelitian tersebut, aktivitas pemasaran yang dilakukan oleh Fruits Up memiliki kesamaan, terutama dengan yang kedua, yaitu pemasaran melalui pemanfaatan media sosial. Meski demikian, perbedaan dari keduanya, produk Fruits Up dipasarkan tidak secara bebas, melainkan di tempat-tempat spesifik, sehingga memerlukan bantuan reseller untuk mencapai sasaran yang tepat.

\section{METODE}

Penelitian ini menggunakan metode kualitatif dengan pendekatan studi kasus. Menurut Mulyana (2006: 201) studi kasus adalah uraian dan penjelasan komprehensif mengenai berbagai aspek seorang individu, suatu kelompok, suatu organisasi (komunitas), suatu program atau suatu situasi sosial.

Menurut Yin (2011: 1) secara umum, studi kasus merupakan strategi yang lebih cocok bila pertanyaan suatu penelitian berkenaan dengan pertanyaan why atau how, bila peneliti hanya memiliki sedikit peluang untuk mengontrol peristiwa yang akan diselidiki, dan bila fokus penelitiannya terletak pada fenomena kontemporer. Studi kasus dapat memberi nilai tambah pada pengetahuan kita secara unik mengenai fenomena individual, organisasi dan politik, studi kasus memungkinkan pneeliti untuk mempertahankan karakter holistik dan bermakna dari peristiwa-peristiwa kehidupan nyata, seperti siklus kehidupan seseorang, proses-proses organisasional dan manajerial, perubahan lingkungan sosial, hubungan-hubungan internasional hingga kematangan industri (Yin, 2011: 4).

Pengumpulan data untuk penelitian ini dilakukan melalui wawancara mendalam kepada sejumlah individu yang terkait dengan pemasaran Fruit Up, yaitu CEO serta Manajer Pemasaran FruitsUp. Data dilengkapi dengan studi pustaka dan observasi. 


\section{HASIL DAN PEMBAHASAN}

Fruits $U p$ merupakan produk UKM Unpad yang dikelola berdasarkan model pemberdayaan Fruters Model, yaitu model pembedayana masyarakat berbasis technology preneurship, yaitu teknologi hasil penelitian yang dirancang dalam bentuk produk bernilai tambah dan diterapkan sebagai penggerak pemberdayaan antar berbagai pemangku kepentingan yang melibatkan akademisi, bisnis, komunitas, pemerintah dan media sehingga memiliki nilai serta dampak positif yang luas. Model ini memetakan kontribusi dan peran para stakeholder dalam menyukseskan program unggulan berbasis kemasyarakatan. Melalui Fruters Model, setiap elemen stakeholder bekerja sesuai posisinya masing-masing sehingga lebih terarah.
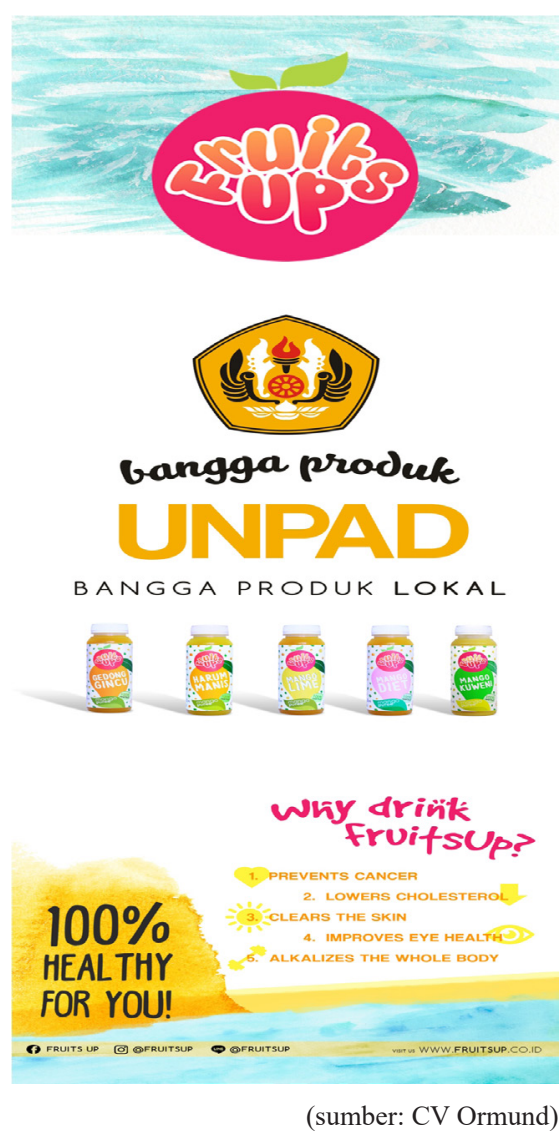

Gambar 1. FruitsUp, produk UKM Unpad

Fruits $U p$ merupakan merek minuman berbasis bubur buah atau puree mangga yang berorientasi pada produk menyehatkan. UKM FruitsUp didirikan berawal dari bagaimana cara meningkatkan nilai tambah dari buah mangga. Mangga yang berasal dari petani di kawasan Ciayumajakuning diubah menjadi puree berkualitas premium.

Pemesanan puree dilakukan secara pre-order kepada pengusaha buah mangga yang berlokasi di Cirebon. Setiap melakukan pemesanan, jumlah puree mangga yang dipesan sekitar 4.230 ton dalam satu tahun, sedangkan kebutuhan per bulannya sekitar 350 liter. Setiap pemesanan puree mangga dilakukan dalam jangka waktu bulan produksi.
Targetnya kelas menengah hingga premium (Purnomo, dkk, 2017).

Dalam menjalankan bisnisnya, CV Ormund sebagai produsen Fruits $U p$, mengusung platform bisnis sosial. Dengan demikian, bisnis yang dijalankan Fruits $U p$ tidak hanya berorientasi pada keuntungan, juga berupaya untuk pemberdayaan masyarakat. Sebagian keuntungan yang diperoleh digunakan sebagai sumber pembiayaan gerakan petani dan komunitas lokal.

Untuk menjaga keberlangsungan bisnisnya, produk harus didistribusikan. Pemasaran dan branding pun dilakukan. Di sinilah pentingnya bagian pemasaran untuk dapat memetakan dan mengatur strategi pemasaran produk, agar Fruits Up dapat terdistribusikan dengan baik dan tepat pada sasaran.

\section{Komunikasi Pemasaran FruitsUp: Offline dan Online}

Pemasaran produk Fruits $U p$ dilakukan melalui dua cara, yaitu secara offline dan online. Secara offline, Fruits $U p$ dipasarkan dengan memberdayakan ibu-ibu rumah tangga di perkotaan sebagai reseller direct selling. Hampir 50 reseller sudah dibina. Mereka pun diajari untuk melakukan pemasaran secara online. "Untuk promosi, branding, mereka juga diajari Instagram, cara advertise di Intagram, advertise di Facebook, dan lain-lain" ujar Mahadian. Selain itu, Fruits Up bekerjasama dengan beberapa outlet, mini market dan cafe di Bandung dan Jakarta sebagai saluran distribusi kepada konsumen.

Dalam sistem pemasaran offline, ada inovasi yang dilakukan, antara lain, reseller diakui sebagai marketing langsung dan dibekali dengan aplikasi yang terafiliasi langsung ke website Fruits $U p$ sehingga dengan mudah, reseller dapat mengecek stock, sisa deposit dan penjualan, serta daerah yang belum terjangkau pemasaran.

Secara online, Fruits $U p$ membuat website yang bertujuan sebagai media untuk mempromosikan produk dan menyampaikan informasi, gambar, video atau lite-lite lainnya terkait profile perusahaan yang dapat diakses semua orang. Website Fruits $U p$ yang sudah dibuat adalah http:// www.fruitsup.co.id .

Sebagai metode branding, informasi yang disampaikan mencakup standar prosedural metode pemasaran melalui media offline maupun online seperti standar logo, cara pemuatan warna, standar desain, serta tata cara penggunaan media.

Pemasaran secara online, dilakukan melalui media sosial Instagram dan Facebook, serta chat messenger Line. Instagram dan Facebook memiliki fitur khusus online marketing seperti Instagram Ads dan Facebook Ads. Fitur tersebut dimanfatkan dengan cara mengunggah foto produk ke media sosial.

Selain itu, Fruits $U p$ bekerja sama dengan salah satu vendor khusus pengiklanan untuk me-repost foto produk dan mengirim broadcast pesan ke aplikasi messenger kepada pelanggan/distributor. Pemasaran online ditugaskan kepada bagian pemasaran. 
Beberapa reseller dilatih melakukan pemasaran online melalui website agar mereka mudah melakukan pemasaran dan branding. Untuk mempercepat pencapaian, tim dari FruitsUp sering mengunjungi reseller untuk menjalin silarurahmi sambil mendapatkan umpan balik tentang pemasaran.

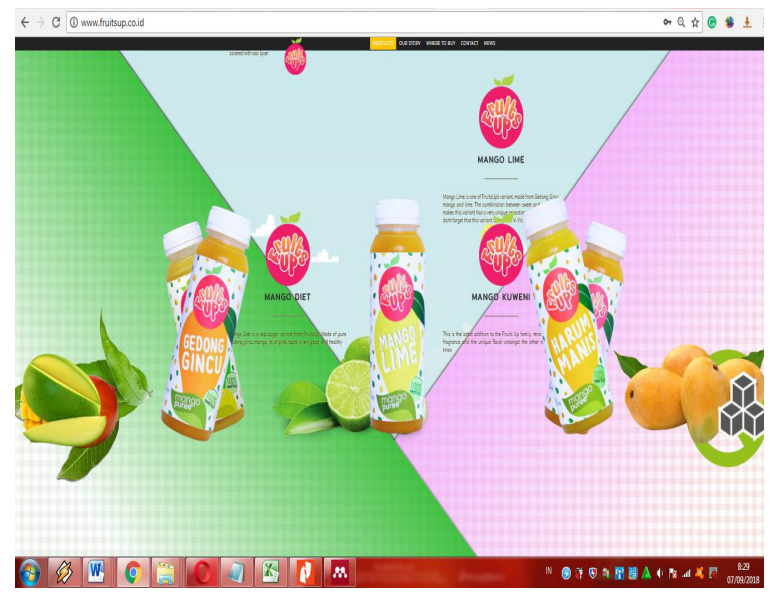

Gambar 2. www.fruitsup.co.id

Selain pemasaran manual, pemasaran berbasis televisi juga dilakukan bekerjasama dengan beberapa stasiun TV nasional dan lokal seperti Metro TV dan MQ TV.

Pemasaran melalui instagram dan facebook dilengkapi dengan tagline dan hastag tentang keunggulan dari produk Fruits $U p$, tips dan informasi tentang kesehatan. Nama akun sosial media yang digunakan yaitu, Facebook: FruitsUp, Instagram: @FruitsUp dan Line: @FruitsUp.

Branding dan pemasaran secara offline dan online yang dilakukan secara terencana dan tertata dengan baik mampu membuahkan hasil. Fruits $U p$ mulai dikenal ke luar Bandung dan Jakarta. Permintaan dari luar pulau pun bermunculan, seperti dari Bali dan Sumatera. Sayangnya, permintaan tersebut belum dapat dipenuhi. Bukan karena produksi tidak ada, melainkan terkendala dalam proses distribusi. Fruit Up yang diproduksi secara alami, tanpa bahan pengawet, tidak bisa bertahan lama jika dibiarkan. "Paling tahan 6 sampai 8 jam di luar tanpa disimpan di kulkas", ujar Mahadiansyah.

Untuk mengantisipasi hal tersebut, telah disiapkan rencana untuk memperpanjang masa simpan dan perluasan distribusi. Untuk memperpanjang masa simpan, akan dilakukan penelitian teknologi pangan, bagaimana memperpanjang masa simpan Fruits $U p$ tanpa bahan pengawet. Sementara untuk perluasan distribusi, direncanakan untuk memiliki mobil pendingin, supaya distribusi dapat dilakukan secara bersamaan ke beberapa kota yang dituju.

\section{Hambatan Pemasaran}

CEO Fruits $U p$, Bambang Bayu, mengatakan, dalam memasarkan produknya, ada beberapa kendala yang ditemui. Selain masa simpan, juga harga yang premium. Kendala dalam masa simpan menyebabkan Fruits $U p$ belum bisa dikirim ke luar wilayah Jatinangor yang membutuhkan waktu lebih dari satu hari. Selain itu, biaya pengiriman menjadi kendala dalam mengirim produk ke luar daerah. Besarnya biaya pengiriman dapat memengaruhi harga jual yang bisa lebih mahal dari yang ditetapkan saat ini, yaitu 15 ribu rupiah per botol.

Diakui Bayu, dengan harga yang ditetapkan sekarang pun, ia sering mendengar keluhan dari beberapa konsumen mengenai harga yang ditetapkan untuk Fruits $U p$. Menurut Bayu, harga jual tersebut sebenarnya sesuai dengan added value yang terdapat dalam Fruits $U p$, yaitu kesehatan yang diperoleh. Selain itu, hasil keuntungan yang diperoleh pun akan digunakan lagi untuk memberdayakan para petani mangga di daerah Ciayumajakuning.

Bayu menambahkan, kualitas produk Fruits $U p$ yang premium, membutuhkan target market yang tepat. Untuk itu, peran reseller sangatlah penting untuk mencapai target market yang sesuai. Ada validasi market yang berkesinambungan. Dari produksi, tidak begitu bermasalah. Hanya masih terkendala di pemasaran. Produksi disesuaikan dengan pemasaran.

\section{Inovasi di Bidang Pemasaran}

Beberapa reseller dibina untuk melakukan branding pemasaran online, yaitu di website. Mereka bisa mudah melakukan pemasaran dan branding. Untuk bergerak lebih cepat, tim dari Fruits $U p$ kerap mengunjungi reseller untuk bersilaturahmi, sekaligus mendapatkan feedback dari mereka mengenai pemasaran yang dilakukan. Untuk lebih mengembangkan usahanya, Fruits $U p$ menjalin jejaring dengan komunitas-komunitas yang ada di Jatinangor dan Bandung. Mereka juga mengikuti workshop.

\section{Perubahan Perilaku Masyarakat}

Perubahan perilaku terjadi tidak hanya pada masyarakat daerah produsen mangga gedong gincu, juga pada masyarakat perkotaan (urban areas) dimana aktivitas pemasaran berlangsung. Masyarakat pedesaan mengalami perubahan perilaku dengan meningkatnya kepedulian terhadap upaya budidaya mangga gedong gincu. Adapun di perkotaan, perubahan perilaku terjadi dalam bentuk mulai meningkatnya motivasi para Ibu rumah tangga terhadap aktivitas pemasaran produk Fruits $U p$. Adanya perubahan perilaku masyarakat di kedua daerah tersebut mendukung terjadinya industrialisasi olahan mangga menjadi lebih massif.

\section{SIMPULAN}

Media massa dan media sosial menjadi saluran komunikasi untuk mengenalkan Fruits $U p$ secara luas. Penggunaan media massa dan jejaring sosial diharapkan selain menjadikan Fruits $U p$ dikenal luas juga dapat memberikan nilai tambah dalam hal pemasaran produk, serta peningkatan kesejahteraan dan kesehatan masyarakat. Peran ibu-ibu reseller pun tidak bisa dikesampingkan, karena melalui mereka pula, Fruits $U p$ dapat dikenal oleh masyarakat yang menjadi target konsumennya. 
Perencanaan yang tepat dan pelaksanaan yang sesuai merupakan kunci dari keberhasilan untuk melakukan pemasaran produk. Ide-ide kreatif yang tiada henti, akan terus mendukung keberlangsungan bisnis yang dijalankan, sehingga semua stakeholder dapat merasakan keberhasilan dari bisnis yang dijalankan.

\section{DAFTAR PUSTAKA}

Deliana, Y., Fatimah, S. \& Charina, A. (2014). Persepsi dan Perilaku Produsen dan Konsumen terhadap Label Asal Daerah pada Mangga Gedong Gincu. Sosiohumaniora, 16, (1), 70-76

Hendri, M. (2009). Pengaruh Komunikasi Pemasaran Terhadap Keputusan Pembelian Teh Kotak Ultra Rasa Melati oleh Remaja di Kota Bandung. The 3rd National Conference on Management System, Bandung, 5 November 2009. Bandung: Universitas Widyatama.

http://repository.widyatama.ac.id/xmlui/bitstream/ handle/123456789/1272/content.pdf? sequence $=103092017$. diakses: 09 September 2017. 18.30 WIB

Mulyana, D. (2006). Metodologi Penelitian Kualitatif. Bandung: Remaja Rosdakarya.

Prayogo, A.. (2015). Komunikasi Pemasaran Usaha Kuliner dalam Menghadapi Persaingan (Studi Deskriptif Kualitatif Kegiatan Komunikasi Pemasaran "Gerobak Cokelat" dalam Menghadapi Persaingan di Kota Solo).

http://www.jurnalkommas.com/docs/JURNAL $\% 20$ K O M U N I K A S I \% 20 A K B A R \% 20 PRAYOGO\%20D0210007.pdf. Diakses 3 September 2017. 18.20.
Purnomo, D., Gunawan, W., Sari, D. \& Susanti, S. (2017). Hilirisasi Model Pemberdayaan "The Fruters Model” Melalui Produk Turunan Puree Mangga Merek FruitsUp. Laporan Riset Hilirisasi Produk Unggulan (RHPU). Jatinangor: Universitas Padjadjaran.

Riyanto, E. dan Triono, A. (2017). Komunikasi Pemasaran Terpadu (IMC) Sekolah Dasar Islam Terpadu di Karanganyar. Komuniti, IX, (1), 44-62. DOI: https://doi.org/10.23917/komuniti.v9i1.4183.

Tsikirayi, C. M. R., Muchenje, B. \& Katsidzira, Z. (2013). Impact of integrated marketing communications mix (IMCM) in small to medium enterprises (SMEs) in Zimbabwe as a marketing tool. Research in Business and Economics Journal, 7, (Imcm), 1-12. Retrieved from: http://search.proquest. com/w/1460230826? accountid $=14495 \% 5 \mathrm{Cn}$ http://diana.uca.es:4550/resserv?genre $=$ articl e\&issn $=\&$ title $=$ Research + in + Business + and + Economics + Journal $\&$ volume $=7 \&$ issue $=\& d a$ te $=$ 2013-02-01\&atitle $=$ Impact + of + integrated + marketing + communications $+\operatorname{mix}$

Yin, R. K. (2011). Studi Kasus: Desain dan Metode. Jakarta : PT Raja Grafindo Persada.

http://www.fruitsup.co.id

https://www.instagram.com/explore/tags/fruitsup

https://www.facebook.com/fruitsupfresh

http://www.unpad.ac.id/2014/11/kembangkansociopreneurship-dosen-ini-dorong-mahasiswadan-masyarakat-berwirausaha. Diakses 6 September 2018 